oedema, were transient and had completely disappeared one year later.

Of particular interest are the haematological findings, as many observers have reported some degree of haemolytic anaemia. In the study by Conrad and colleagues all 25 patients had normal levels of haemoglobin on admission-that is, within five days of the appearance of jaundice. In 19, however, there was a fall in the packed-cell volume of over $10 \%$ within the next three weeks, accompanied by a moderate rise in reticulocytes. The haemolytic nature of the anaemia is supported by the observation that in six patients in whom the reticulocytosis persisted for more than two months there was a concomitant rise in serum bilirubin and a fall in the red-cell survival time. There is no evidence that autoimmunity plays any part in the development of the anaemia, and the Coombs test was consistently negative. The ability of many viruses to agglutinate various species of red cells ${ }^{3}$ raises the possibility that the anaemia is a direct result of viral action upon red-cell receptors. The agglutination of chickembryo red cells by the serum of patients with infectious hepatitis ${ }^{4}$ offers some support for this hypothesis, but doubt is thrown on it by the similar effect of sera from patients with other forms of hepatic disease. ${ }^{5}$

Extrahepatic effects of the hepatitis virus apart from those on the blood and haemopoietic tissues have previously been noted almost exclusively in post-mortem material from fulminant cases. They include phlegmonous enteritis, ${ }^{6}$ pancreatitis, ${ }^{7}$ and myocarditis. ${ }^{8}$ It is now evident that even typical cases running a normal course should be regarded as examples of a systemic disease in which the liver is only one of the organs affected, albeit the most conspicuously.

\section{Replacement of Heart Valves}

The replacement of severely damaged aortic and mitral valves has greatly improved the treatment of acquired valvular disease of the heart in the last few years. Though closed transventricular valvotomy still remains the most widely used method of treating stenosis of the mitral valve, replacement of the valve is being used increasingly to treat recurrent stenosis and very heavily calcified valves. Severe mitral incompetence could not be relieved surgically until the introduction of cardio-pulmonary bypass. Many methods of repairing the incompetent valve by suture and support with prosthetic inserts were tried without much success, until G. H. Wooler and his colleagues ${ }^{1}$ described a successful operation for dealing with cases of pure incompetence due to a dilated annulus but with functioning valve cusps. In most cases, however, the cusps are destroyed, shrunken, or calcified, and these patients are now best treated by valve replacement.

The most widely used and successful valve so far developed is that designed by A. Starr and his colleagues ${ }^{2}{ }^{3}$ in the United States. It consists of a silicone-rubber ball in a cage, which prevents its flying off in systole and allows the blood to flow round it. In diastole the ball fits into a socket-shaped ring, which occludes the atrio-ventricular canal and prevents regurgitation. The ring has a plastic fabric outer ring and is fixed to the annulus of the mitral valve by numerous stitches passed through this fabric. Patients treated by Starr have now been followed up for some years and the great clinical improvement produced by the successful insertion of the valve appears to be well maintained. This does not mean that the operation should be undertaken lightly. The operative mortality in the most experienced centres varies between $5 \%$ and $20 \%$, and there is a risk of serious embolism in some patients in the first year after operation. At present before operation is considered it should be shown that medical treatment can no longer prevent deterioration of the patient's condition.

C. N. Barnard and his colleagues ${ }^{4}$ in South Africa have described excellent results with a different design of prosthesis, and recently D. G. Melrose and his colleagues ${ }^{5}$ in Britain have reported encouraging preliminary results with a prosthesis which eliminates the caged ball in the ventricular cavity. Thus replacement of the mitral valve in some cases of mitral stenosis and most cases of mitral incompetenceor in the combined lesion-is now feasible. As with all new surgical procedures increasing experience will steadily decrease the mortality, and it may be that in a year or two valve replacement will be used in less severe cases.

Aortic stenosis was initially treated by transventricular aortic valvotomy, ${ }^{6}{ }^{7}$ with good results in about $50 \%$ of cases, improvement in $35 \%$, and a mortality of $15 \%$. Most surgeons now agree, however, that aortic stenosis is best dealt with under direct vision and using cardio-pulmonary bypass. The surgeon has a choice between commissurotomy and debridement, on the one hand, and valve replacement on the other. The former is usually all that is necessary $j_{1}$ children and young adults with congenital aortic stenosis.

Calcific aortic stenosis or aortic incompetence o: both remain the most difficult problems. Debridement of calcium has a definite place still, but aortic incompetence can be treated only by open operation, and valve replacement is now recognized to be the only effective method. Neither the use of one, two, or three plastic cusps to replace the natural cusps, as advocated by $\mathrm{H}$. T. Bahnson and his colleagues, ${ }^{8}$ nor the use of a McGoon plastic sleeve ${ }^{9}$ have stood the test of time. Though the initial results were good a very high incidence of restenosis of these plastic valves occurred one to two years later. At the present time, therefore, there are two successful methods available. The first is the use of the Starr-Edwards caged-ball prosthesis. ${ }^{10}$ This is similar to the type used to replace the mitral valve, but the shape is modified to fit the aortic ring. Its method of insertion is the same, and it is placed below the openings of the coronary arteries after the aortic cusps have been excised. This is the more widely used method and good results have been reported from many centres with an operative mortality rate of $20 \%$ or less. 1 Wooler, G. H., Nixon, P. G. F., Grimshaw, V. A., and Watson, D. A.,
Thorax, 1962, 17, 49.

${ }^{2}$ Starr, A., and Edwards, M. L., F. thorac. cardiovasc. Surg., 1961, 42, 673.

${ }^{3}$ McCord, C. W., and Starr, A., Trans. XIV Congress of the International College of Surgeons, p. 177, 1964 .

${ }^{4}$ Barnard, C. N., Goosen, C. C., Holmgren, L. V., and Schrire, V., Lancet, 1962, 2, 1087.

${ }^{5}$ Melrose, D. G., Bentall, H. H., McMillan, I. K. R., Flege, J. B., Alvarez Diaz, F. R., Nahas, R. A., Fautley, R., and Carson, J., ibid., 1964, 2, 623.

${ }^{6}$ Bailey, C. P., Bolton, H. E., Jamison, W. L., and Nichols, H. T., Circulation, 1954, 9, 22.

' Brock, R., Brit. med. F., 1956, 1, 1019.

${ }^{8}$ Bahnson, H. T., Spencer, F. C., Busse, E. F. G., and Davis, F. W., Ann. Surg., 1960, 152, 494.

9 McGoon, D. C., Proc. Mayo Clin., 1961, 36, 88.

${ }^{10}$ Starr, A., Edwards, M. L., McCord, C. W., and Griswold, H. E., Circulation, 1963, 27, 779 .

${ }^{11}$ Murray, G., Angiology, 1956, 7, 466.

12 Ross, D. N., Lancet, 1963, 1, 571.

${ }^{13}$ Starr, A., McCord, C. W., Wood, J., Herr, R., and Edwards, M. L., Ann. Surg., 1964, 160, 596. 
The other method is the replacement of the aortic valve by a homograft valve. This was first done by Gordon Murray $^{11}$ in Toronto in 1956, with good results so far, and the method has also been used in Britain by D. N. Ross, ${ }^{12}$ using reconstituted freeze-dried homografts, and in New Zealand by Barrett Boyes. The great theoretical advantage of the homograft valves is that they are soft and pliable and copy the original exactly. The prosthetic valve, on the other hand, requires a rigid framework and in the long term this may be found to be a disadvantage, though at present there is no evidence of this.

The tricuspid valve can be replaced in the same way as the mitral valve, but so far there has been no indication for pulmonary-valve replacement. It is possible, and sometimes necessary, to replace two valves at once ${ }^{13}$ - and even three valves have been replaced-though the mortality rate obviously rises steeply in these patients, who are usually desperately ill.

Surgical replacement of heart valves is a field of rapid progress and probably represents the last major advance in cardiac surgery before the final stage of total replacement of the heart, but this is still some time away.

\section{Report on Poisons}

There are now four official centres in Britain (in London, Edinburgh, Belfast, and Cardiff) which can supply doctors with details of the toxic effects of various substances that their patients may have taken and how to treat them. The first three centres began operating in September $1963^{1}$ - ten years after the first centre in the world opened at the Presbyterian St. Luke Hospital in Chicago and two years after the voluntary centre at Leeds ${ }^{2}$ had started-and the centre at Cardiff opened in March $1964 .{ }^{3}$

The first annual report of the National Poisons Information Service ${ }^{4}$ shows that the centres have supplied a need. Though some people have criticized the restriction of inquiries to doctors, ${ }^{5}$ the report justifies this on two grounds-firstly that no one who may have been poisoned can be properly treated without being seen by a doctor, and secondly that many manufacturers have supplied details of their products only because they knew that these would be confidential. All the centres work in roughly the same way. All calls are answered initially by the secretary of the centre or by a senior nurse ; further comment by a medical officer may be necessary; and an expert adviser is always available for consultation. Every doctor who uses the service is sent a questionary about the incident, so that valuable follow-up details are obtained. Altogether 2,101 inquiries were answered by telephone, and most of these dealt with medicines and household products. Two-thirds of the inquiries were about children, and the report emphasizes that an unpleasant taste or odour does not usually prevent them from sampling a substance, though ordinary household products are rarely lethal. In adults a particularly frequent mishap is reported to be the mixing of

\footnotetext{
1 Brit. med. F., 1964, 1, 450.

Ellis, M., ibid., 1964, 1, 627.

- Graham, J. D. P., ibid., 1964, 1, 627

- Goulding, R., and'Watkin, R. R., Mth. Bull. Minist. Hlth Lab. Serv., $1965,24,26$.

s Sweetnam, W. P., Brit. med. F., 1964, 1, 627.
}

two proprietary lavatory cleaners (one containing bisulphate, the other hypochlorite), resulting in the liberation of fumes, mainly chlorine, which give rise to acute irritation of the upper respiratory tract. There were 33 deaths, of which 26 were due to drugs, and the majority of these were suicidal. But most of the patients with so-called poisoning were in no danger, and a valuable part of the service was to relieve anxiety and to prevent unnecessary treatment. Clearly these centres should do much to raise the standards of treatment of poisoning in Britain.

\section{Man or Mouse-or Both}

In the process of sexual reproduction two specially modified cells unite to form a zygote. Though widespread in the plant and animal kingdoms this form of reproduction is far from universal. Nor is the uniting of cells restricted to those which have been modified to take part in sexual reproduction. Among the fungi somatic cells may fuse in the natural state or in experimental cultures. Somatic cells in animals are not known to form hybrids of this kind in nature, but in the laboratory they can be induced to do so.

Within the last few years two separate groups, in France and in the U.S.A., have produced mating between somatic cells of the mouse grown in tissue culture. G. Barski' grew two lines of mouse-tumour cells which had complements of chromosomes that could easily be distinguished from each other. The N1 line (an easily transplantable malignant line) had about 55 chromosomes and the N2 line (of low malignancy) 62-65. In mixed culture true hybrids could be discerned. These could be further cultured -in other words, the hybrid nuclei could divide. And in form the progeny were intermediate between the cells of the parents. They retained the high malignancy for mice of N1 cultures and had 95-100 chromosomes. The American group, headed by B. Ephrussi, ${ }^{2}$ also used mouse-tumour cells. They were able to show by analysis of the chromosomes that mating had occurred between N2 cells and a cell line, transformed by polyoma virus, from a different strain of mouse. On culture these hybrid mouse cells had lost some of the chromosomes that had been present originally. Moreover, these cells carried four iso-antigens, three derived from one parental line and one from the other, together with the antigens characteristic of the virus-transformed line. ${ }^{3}$

Now Professor Henry Harris and Dr. J. F. Watkins, of the Sir William Dunn School of Pathology at Oxford, have reported some remarkable experiments in which they got cells from entirely different mammalian species to fuse. ${ }^{4}$ They have produced heterokaryons between cells originating from man and mouse. A heterokaryon is a cell containing two different nuclei in the cytoplasm, whereas the cytoplasm of a hybrid cell contains only one nucleus. Harris and Watkins's cells were in fact from the HeLa line, grown from a carcinoma of the human cervix uteri, and from the Ehrlich's ascites tumour derived from a mouse.

\footnotetext{
Barski, G., Symp. internat. Soc. Cell Biol., 1964, 3, 1.

Ephrussi, B., Scabetta, L. J., Stenchever, M. A., and Yoshida, M. C., ibid., 1964, 3, 13.

Defendi, V., Ephrussi, B., and Koprowski, H., Nature (Lond.), 1964, 203, 495 .

+ Harris, H., and Watkins, J. F., ibid., 1965, 205, 640.

Marston, R. Q., Proc. Soc. exp. Biol. (N.Y.), 1958, 98, 853.
} 